\title{
Efektivitas strategi komunikasi pemasaran celebrity endorsement di Instagram terhadap generasi $\mathbf{Z}$
}

\author{
Nadia Febriani \\ Universitas Indonesia, Jakarta, Indonesia
}

\begin{abstract}
ABSTRAK
Celebrity endorsement merupakan salah satu strategi komunikasi pemasaran dengan melibatkan tokoh terkenal yang memberikan ulasan produk atau brand dalam bentuk konten promosi ke pengikutnya. Pada praktiknya, banyak artikel mengatakan bahwa Generasi Z sebagai konsumen dominan memiliki karakteristik berbeda dari generasi sebelumnya sehingga tidak lagi menyukai bentuk promosi endorsement. Oleh karena itu penelitian ini bertujuan untuk mengetahui dan membuktikan penilaian Generasi Z (lahir pada tahun 1995-2010) terhadap efektivitas pada strategi komunikasi pemasaran celebrity endorsement. Metode yang digunakan adalah mixed method tipe sequential explanatory strategy yang didahulukan dengan pengumpulan data kuantitatif dan dilanjutkan dengan pengambilan data kualitatif. Responden berjumlah 100 orang dari populasi Mahasiswa Ilmu Komunikasi Universitas Padjadjaran yang lahir pada tahun 2000-2002. Hasil menunjukkan bahwa penilaian Generasi $\mathrm{Z}$ terhadap efektivitas penggunaan bentuk strategi komunikasi pemasaran celebrity endorsement relatif rendah. Hal ini disebabkan oleh beberapa hal, di antaranya pengemasan konten yang monoton dan tidak kreatif, pemilihan selebgram yang tidak disesuaikan dengan katagori brand yang diiklankan, ulasan yang bukan hasil penggunaan sebenarnya, konten endorsement yang terlalu banyak (spamming), serta kualitas visual yang tidak berkualitas. Responden menyarankan beberapa contoh penerapan celebrity endorsement yang direkomendasikan seperti@joviadhiguna,@rezachandika,@ ojmo,@megaiskanti,@agunghapsah,dan lain-lain.
\end{abstract}

Kata-kata kunci: Celebrity endorsement; efektivitas konten; selebgram; generasi z; komunikasi pemasaran

\section{The effectiveness of celebrity endorsement marketing strategy on Instagram from generation $Z$ 's perspectives}

\begin{abstract}
Celebrity endorsement is one of the marketing communication strategies used by brands or companies, involving well-known person and their social media status to promote a product or service by content review as a promotional campaign to their followers. Recent articles said that Generation $Z$ as the dominant consumer has different characteristics from the previous generation which no longer believes the form of endorsement as promotional messages. This study aims to find out and prove the perceptions of Generation $Z$ (born in 1995-2010) for the effectivity of the celebrity endorsement marketing strategy. The method used in this study is a mixed method sequential explanatory strategy which conducts the quantitative data collection and continued by qualitative data results analysis. The sample conducts 100 students from Fakultas Ilmu Komunikasi Universitas Padjadjaran whose born at 2000-2002. The result showed that Generation Z's evaluation of the effectiveness of using the form of celebrity endorsement is relatively low. Several reason concludes that endorsement forms contains monotonous and non-creative content creation, incompetence of the celebrity endorsement that did not match the brand categories \& values, the reviews that are not actually based by daily using, the overcontent of endorsement post, and the bad visuals quality. Generation $Z$ also suggested some of the good celebrity endorsement practicessuchas@joviadhiguna,@rezachandika,@ ojmo,@agunghapsah, andsoon.
\end{abstract}

Keywords: Celebrity endorsement; content effectiveness; Instagram celebrity; generation z; marketing communication

Korespondensi: Nadia Febriani, S.I.Kom. Universitas Indonesia. Jalan Salemba Raya No 4, Jakarta, Indonesia.10430.Email: nadiafeb19@gmail.com 


\section{PENDAHULUAN}

Dalam industri komunikasi pemasaran, penilaian pengguna menjadi komponen penting yang harus diperhatikan dalam memperoleh kepercayaan merek bagi calon pembeli berkelanjutan. Saat ini, calon pembeli secara aktif mencari informasi terkait ulasan produk dan jasa dalam menentukan pilihan. Informasi diperoleh dari situs resmi, kolom ulasan, kerabat, dan media sosial (Childers et al., 2019).

Perkembangan teknologi dan proses digitisasi membawa perubahan yang besar pada pola pertukaran informasi dan komunikasi (Drago, 2015). Adrianson \& Hjelmquist menyebut pergeseran ini bertransformasi dari analog tatap muka atau face-to-face communication menjadi komunikasi termediasi dengan perangkat digital atau computer mediated communication. Proses digitalisasi membawa transformasi pada sektor promosi pada industri pemasaran, yakni pada bentuk penyampaian pesan komunikasi Word of Mouth (WOM). WOM dinilai sebagai referensi yang paling efektif bagi calon pembeli dalam mendengar ulasan produk dan jasa (Jankowski, 2013).

Salah satu strategi WOM yang dinilai efektif adalah menggunakan tokoh terkenal dan berpengaruh. Terbukti pada tahun 2017 sektor industri pemasaran digital yang menyediakan layanan promosi brand atau produk melalui tokoh terkenal seperti influencer agency memiliki nilai valuasi yang tinggi yakni ditaksir mencapai angka dua milyar dollar dan diprediksi terus berkembang hingga mencapai nilai sepuluh milyar dollar pada akhir tahun 2020 (Garcia, 2017; Adweek, 2018).

Strategi komunikasi pemasaran yang memanfaatkan ketenaran seseorang di sosial media disebut dengan istilah celebrity endorsement (Mulyo, 2016). Penggunaan strategi celebrity endorsement merujuk pada sebuah bentuk promosi yang dilakukan tokoh dengan popularitas tinggi di sosial media dalam bentuk penyampaian pesan ulasan terkait brand atau produk yang dipromosikan (Ridha et al., 2018). Sosok yang dipilih sebagai celebrity endorser merupakan sekelompok orang yang terkenal karena menguasai keahlian tertentu atau merupakan praktisi yang berpengaruh pada bidangnya (Childers, 2019). Berbeda dengan bentuk pemasaran menggunakan pesan iklan konvensional, strategi celebrity endorsement menempelkan keterikatan dan hubungan antara celebrity endorser dengan pesan brand yang dipromosikan (Rahmawati \& Lestari, 2021).

Pada praktiknya, penerapan strategi komunikasi pemasaran menggunakan model celebrity endorsement tidak disertai dengan kualitas dan kesesuaian esensi ide pesan dengan latar belakang endorser dan gaya hidupnya 
(Ramadhan et al., 2020). Pada sebagian besar pelaksanaan praktik celebrity endorsement di Instagram, pemasar hanya meminta jasa dari Instagram celebrity atau yang dikenal dengan istilah selebgram untuk memposisikan produk atau brand-nya dengan foto dan video yang diunggah pada media sosialnya. Pengiklan tidak lagi memperhatikan konteks dengan keahlian atau latar belakang dari celebrity endorsement yang digunakan, melainkan menggunakan format template caption seperti yang tergambar pada salah satu unggahan selebgram @ marcoivanos12 yang melakukan kerja sama endorsement dengan brand Tokopedia seperti pada gambar 1.

Belch \& Belch (2017) mengatakan penggunaan selebgram dapat meningkatkan efektivitas jika memuat kesesuaian antara latar belakang selebgram dengan nilai (value) pesan promosi brand yang diiklankan. Pada tahun 2019, data yang dihimpun lembaga riset $W e$ Are Social (Greenwood, 2019) menemukan bahwa Generasi Z (kelahiran 1995 - 2010) tidak lagi percaya pada strategi komunikasi pemasaran endorsement. Gen Z lebih menyukai orang-orang yang memiliki keahlian atau kisah inspiratif dalam bentuk aksi nyata, tidak hanya sekadar unggahan foto dan video yang sangat menonjolkan pesan iklan.

Studi terkini mengemukakan bahwa popularitas seorang influencer tidak lagi menjadi daya tarik utama, melainkan ide dari influencer tersebut harus dapat menginspirasi dan relevan dengan pesan iklan produk/brand yang

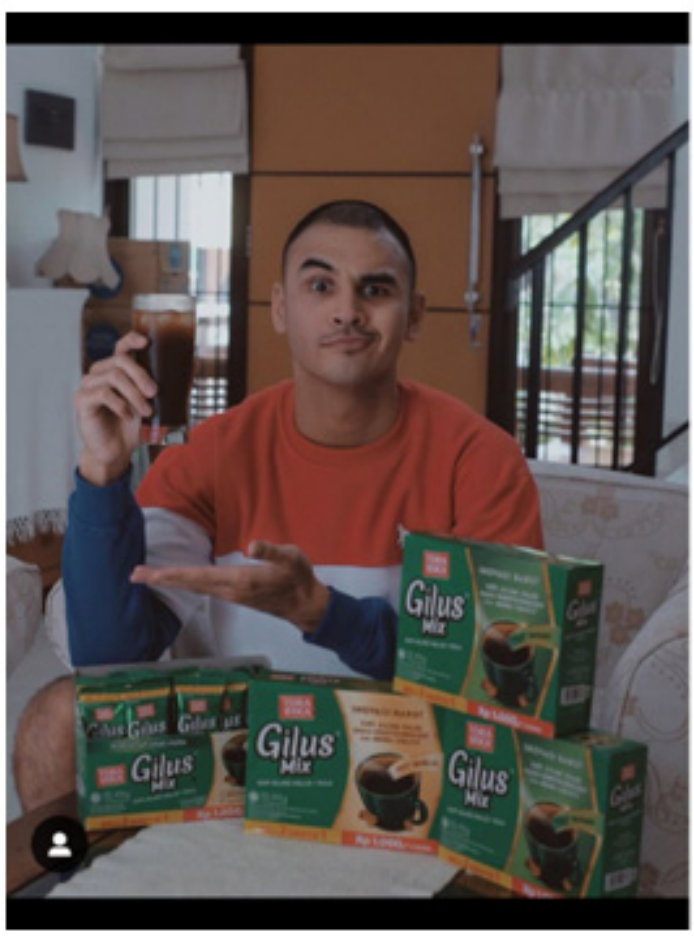

Sumber: Akun Instagram @marcoivanos12 marcoivanos12 • Follow Paid partnership with tokopedia Di Depan Rumah Pak Botak

marcoivanos12 $\odot$ Gua kalo buka puasa, wajib banget ngopi asli dah, kalo kaga kaya nyawa gua di antah berantah gitu kaya hampir kesurupan aing maung.

Ini nikmat sih emang Kopi Gilus Mix, kopi hitam aroma gula aren gitu, sedep bener dah ah.

Jadi kopinya digiling halus, terjadilah ampasnya cepet turun kaga ganggu kehidupan kerongkongan kita.

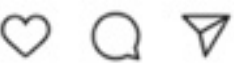

Liked by sefiiin and others

MAY 15

Gambar 1 Foto Unggahan Marco Ivanos 
dipromosikan, sehingga dapat lebih menyentuh minat dan sisi emosional konsumen potensial (Santoso, 2020). Fakta baru ini menunjukkan bahwa walaupun generasi $\mathrm{Z}$ terbuka dengan bentuk pemasaran melalui jejaring media sosial, namun mereka akan lebih percaya dan reseptif jika pesan yang disampaikan influencer tersebut dapat terhubung atau sesuai dengan hal-hal yang disukai dan menginspirasi kehidupan Generasi Z.

Generasi Z, dengan karakteristik yang kritis dan terbuka menilai bahwa penerapan celebrity endorsement hanya dilatarbelakangi oleh motif uang daripada memberikan asosiasi yang tepat antara value hidup celebrity endorser dengan pesan atau value pada brand yang dipromosikan (Belch \& Belch, 2017).

Oleh karena itu, penelitian ini bertujuan untuk mengetahui dan membuktikan bagaimana pandangan Generasi Z terkait efektivitas strategi komunikasi pemasaran celebrity endorsement di Instagram yang terjadi di Indonesia saat ini. Penilaian efektivitas celebrity endorsement diharapkan dapat menjadi bahan referensi dan evaluasi bagi para praktisi pemasaran yang bertujuan untuk menyasar minat dari Generasi Z sebagai calon konsumen potensial yang akan mendominasi perputaran perekonomian di masa mendatang (Budiman \& Erdiansyah, 2021). Ini perlu dilakukan untuk dapat menyasar target konsumen dengan lebih tepat sasaran.
Salah satu cara yang dapat digunakan untuk menyasar generasi $\mathrm{Z}$ adalah dengan WOM. Word of Mouth (WOM) didefinisikan sebagai percakapan tatap muka antara konsumen mengenai pengalaman terhadap produk atau brand tertentu (Sen \& Lerman, 2007). Percakapan tatap muka ini biasanya bersifat pribadi dan dilakukan antara dua pihak, yakni sumber informasi dan penerima (Gilly et al., 1998). Komunikasi ini terjadi di ruang lingkup kerabat dekat seperti keluarga, teman, atau orang kepercayaan. Pada awalnya WOM merupakan aktivitas yang terjadi secara natural dan independen, tidak didasari oleh kepentingan komersial untuk bertujuan menguntungkan salah satu pihak.

Hennig-Thurau mendefinisikan eWOM sebagai pernyataan positif atau negatif yang disampaikan melalui internet oleh konsumen unggul, konsumen aktual, atau mantan konsumen mengenai produk atau jasa yang dipasarkan (Hennig-Thurau et al., 2004). Kata kunci yang membedakan $e W O M$ dengan $W O M$ adalah penggunaan medium perantara yang terkoneksi internet sehingga masyarakat global dapat saling berbagi pendapat melalui platform online (López \& Sicilia, 2014a). Pertukaran informasi melalui perangkat digital online dilakukan dilakukan melalui medium Web 2.0, salah satu yang paling sering digunakan adalah jejaring media sosial (Kaplan \& Haenlein, 2010) 


\section{WOM}

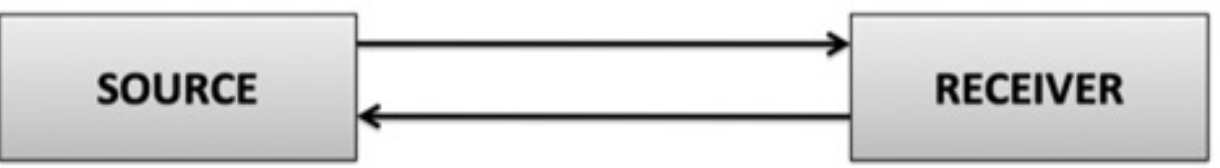

E-WOM

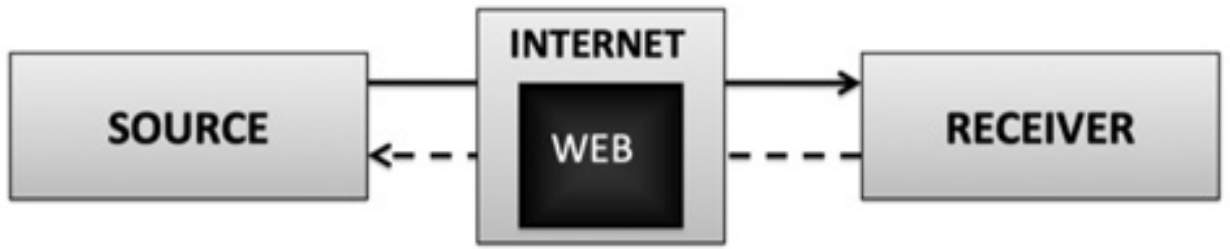

Sumber: López \& Sicilia, 2014

Gambar 2 Perbandingan Proses Komunikasi WOM dengan eWOM

seperti blog, Instagram, Twitter, YouTube, dan lain-lain (Sammis et al., 2015). Perbandingan proses komunikasi yang terjadi di $W O M$ dan eWOM dapat dilihat di Gambar 2.

Pada awal komersialisasi bentuk WOM banyak digunakan pada sektor kehumasan untuk membantu organisasi dalam membentuk kesadaran di masyarakat mengenai program kampanye atau sosialisasi suatu ide tertentu (Hennig-Thurau et al., 2004). Dengan perkembangan yang sangat pesat dan dirasa menjadi bentuk strategi komunikasi yang efektif dalam mempengaruhi orang lain, WOM banyak diadaptasi oleh pelaku industri pemasaran dengan bentuk pemasaran melalui medium sosial media atau eWOM. Bentuk pemasaran dengan menggunakan strategi komunikasi pemasaran model $e W O M$ dinilai lebih efektif dibanding dengan bentuk pemasaran model iklan konvensional (McMillan \& Childers,
2017).

Apapun cara yang digunakan, semua memerlukan strategi agar efektif mencapai tujuan pemasaran. "Winning nowadays requires strategy and squeezing the most out of every opportunity.”, demikian diungkapkan Matt Warren, 2020, Founder \& CEO of Veeqo.

Kutipan itu menggambarkan peran komunikasi pemasaran sebagai sebuah strategi dalam memenangkan kontestasi pasar. Strategi merupakan rumusan rencana yang dikelola, disatukan, dan diintegrasi dengan menghubungkan peluang, keunggulan strategis, kelemahan, dan kendala pasar, serta dirancang untuk memberikan kepastian dan tata cara bagi perusahaan sehingga dapat dilaksanakan dan mencapai tujuan perusahaan (Glueck \& Jauch, 1989). Sehingga, strategi pada komunikasi pemasaran memungkinkan sebuah organisasi untuk menentukan cara yang tepat dalam 
memasarkan ide atau pesan yang direncanakan.

Proses komunikasi yang terjadi pada komunikasi pemasaran dapat diidentifikasi dari proses penyampaian pesan dari pengirim kepada penerima di mana di dalamnya terjadi proses encoding yang merupakan proses merancang dan mengubah rancangan gagasan menjadi sebuah pesan atau ide, serta proses decoding yang merupakan proses penerimaan dan pemaknaan pesan tersebut oleh penerima pesan. Dalam proses komunikasi pemasaran, dibutuhkan perantara sepertimedia (transporter) pesan komunikasi. Komponen penting dalam identifikasi sistem pada strategi komunikasi pemasaran dapat dilihat pada gambar 3 . mengimplementasikan konsep eWOM adalah pada strategi promosi Influencer Marketing. Sosok Influencer Marketing merupakan sekelompok orang yang terkenal karena menguasai keahlian tertentu atau merupakan praktisi yang berpengaruh pada bidangnya (Childers et al., 2019). Strategi penyampaian pesan melalui influencer dinilai sangat efektif, hingga pada tahun 2017 sektor industri seperti influencer agency memiliki nilai valuasi yang tinggi yakni ditaksir mencapai angka dua milyar dollar dan diprediksi terus berkembang hingga mencapai nilai sepuluh milyar dollar pada akhir tahun 2020 (Garcia, 2017; Adweek, 2018).

Menariknya, terdapat sekitar 95\% pemasar Salah satu strategi pemasaran yang menggunakan strategi pemasaran eWOM

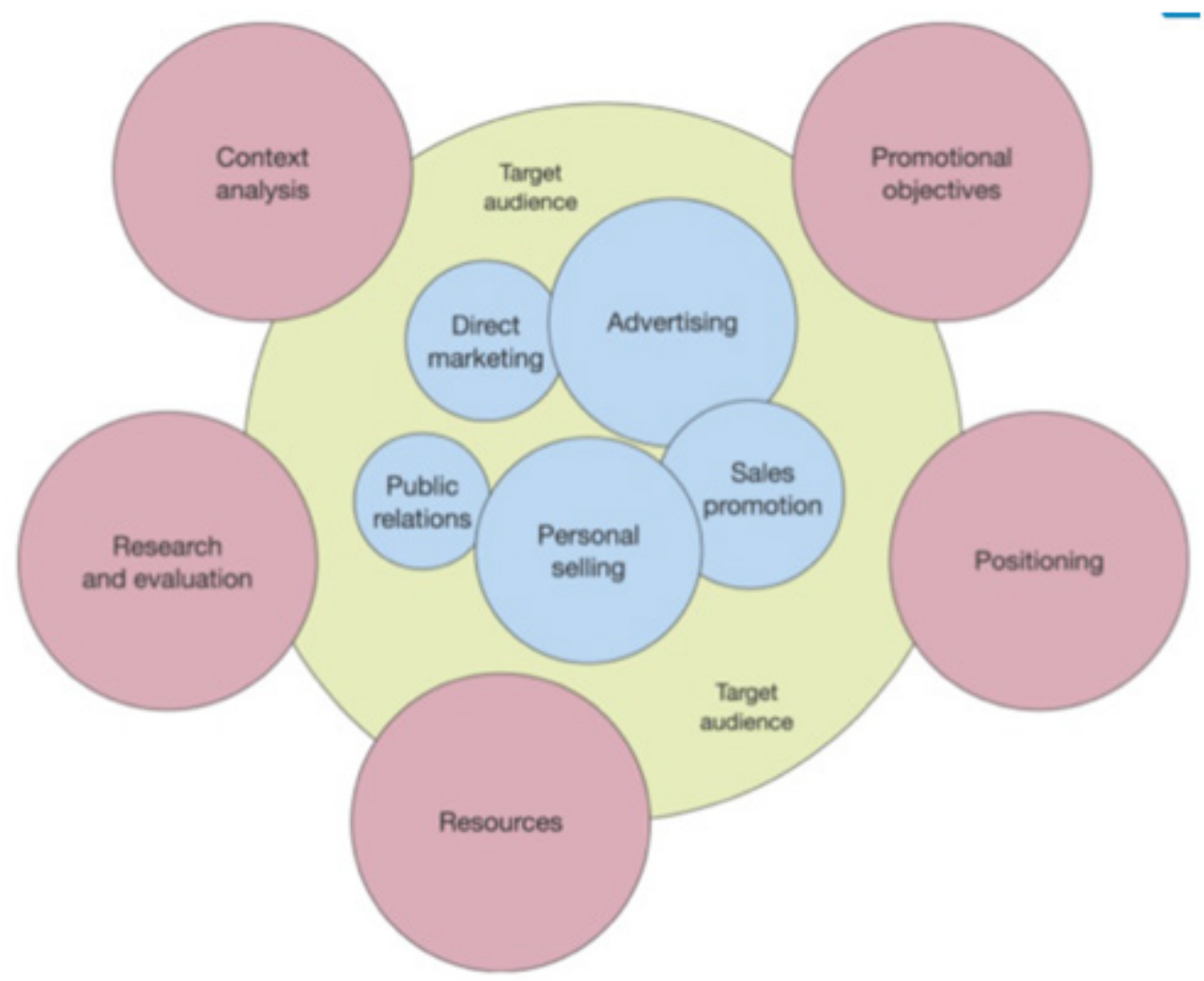

Sumber: Arvind Pawar, 2014

Gambar 3 Komponen Penyusun Sistem pada Komunikasi Pemasaran. 
influencer di Instagram Sammis et al., (2015). McCracken menyebut strategi komunikasi pemasaran yang memanfaatkan ketenaran seseorang di sosial media Instagram dengan istilah celebrity endorsement . Penggunaan strategi celebrity endorsement merujuk pada sebuah bentuk promosi yang melakukan asosiasi simbolik pada tokoh yang memiliki popularitas di Instagram dengan produk atau brand yang dipromosikan (McCracken, 1989).

Selebritas Instagram yang melakukan praktik strategi celebrity endorsement dalam promosi suatu produk disebut sebagai celebrity endorser (Friedman \& Friedman, 1979). Endorser merupakan salah satu bentuk influencer marketing yang berfungsi untuk menyampaikan pesan ke pengikutnya mengenai suatu produk dan membantu pembentukan karakter brand sehingga dapat membedakan antara persaingan merek satu dengan merek lainnya (Belch, et al., 2009). Endorser dapat berasal dari selebriti maupun bukan selebriti. Sebagai komunikator, endorser atau penyampai pesan diharapkan dapat memberikan citra yang baik untuk sebuah brand sehingga dapat memberikan kesesuaian antara selebriti dengan nilai-nilai brand.

Belch \& Belch mengatakan bahwa dalam implementasi strategi pemasaran, celebrity endorsement dapat meningkatkan efektivitas iklan jika terdapat kesesuaian antara karakter celebrity dengan nilai-nilai dari brand yang diiklankan (Belch \& Belch, 2017). Dalam merancang implementasi strategi pemasaran celebrity endorsement, pengiklan perlu mempertimbangkan indikator-indikator yang dapat memberikan dampak positif bagi pelaksanaan iklan yang dilakukan. Indikator tersebut menjadi tolak ukur sejauh mana efektivitas celebrity endorsement dapat diterima oleh target khalayaknya. Dalam mengukur tingkat efektivitas penggunaan strategi pemasaran celebrity endorsement dapat dilihat dari beberapa indikator, yang pertama adalah indikator kredibilitas.

Beberapa pakar, di antaranya Ohanian, (1990), mengatakan bahwa kredibilitas pesan iklan yang disampaikan tergantung pada tingkat keahlian dan kepercayaan dari celebrity endorser yang digunakan. Ohanian, (1990) mendefinisikan kredibilitas celebrity endorser sebagai sejauh mana celebrity endorser dilihat mempuyai kesesuaian antara pesan iklan dengan latar belakang kesehariannya sehingga dapat dilihat kesungguhan dan kejujuran saran yang objektif terhadap produk. Dimensi pertama dari kredibilitas adalah kepercayaan (trustwothiness) yang merepresentasikan informasi yang disampaikan dengan jujur dan objektif.

Dimensi selanjutnya dari kredibilitas (McCracken, 1989) adalah daya tarik 
(attractiveness) yang merepresentasikan atribut yang menarik dari celebrity endorser yang dapat diukur dari familiarity (dilihat dari sejauh mana khalayak mengenal celebrity endorser yang digunakan brand), likeability (merupakan tingkatan yang menimbulkan pengaruh, atensi, dan dampak positif terhadap pesan berdasarkan atribut fisik celebrity endorser), familiarity (kesamaan khalayak dengan celebrity endorser), dan attractiveness (daya tarik dari aspek internalisasi seperti tingkat intelektual, keahlian, cara pandang, dan sebagainya). Dimensi terakhir dari indikator kredibilitas adalah keahlian (expertise). Shimp mengemukakan bahwa keahlian sebagai faktor penting yang dapat menangkap atensi khalayak karena keahlian dianggap realita yang menunjukkan kehidupan sebenarnya. Keahlian dapat mengundang khalayak untuk turut membentuk keterampilan, memberikan kesesuaian wawasan serta pengalaman yang dimiliki celebrity endorser untuk dihubungkan dengan pesan (value) dari konsep produk yang diiklankan (Shimp et al., 2007).

Indikator selanjutnya dikemukakan oleh Kamins yang mengatakan bahwa penyampaian pesan iklan yang efektif dapat didapat dari asosiasi yang sesuai antara celebrity endorser dengan fitur produk atau brand yang diiklankan sehingga dapat saling memberikan komplemen (Kamins, 1990). Dengan kata lain, jika celebrity endorser dengan pesan iklan dapat dihubungkan dengan sukses maka citra brand dapat mendapat dampak yang positif sehingga penerapan iklan dapat berjalan dengan efektif (Bertrand, 1992). Indikator terakhir disampaikan oleh McCracken yang mengangkat tentang familiarity, di mana iklan yang efektif harus dapat menyampaikan konteks pesan sebagai konten yang berkualitas sehingga dapat memberikan makna pada pesan yang disampaikan dan dapat diterima oleh khalayak (McCracken, 1989).

Di sisi lain, Kupper Schmidt mendefinisikan generasi sebagai sebuah periode pengelompokan manusia berdasarkan masa waktu lahir, usia, lokasi, dan penyebab peristiwa dalam suatu kelompok individu (Kupper Schmidt, 2000). Setiap generasi menandakan pembeda tertentu pada tiap fase pertumbuhan (Sofwan, 2013). Dalam teori generasi pengelompokan generasi manusia dibedakan berdasarkan tahun kelahirannya, di mulai dari Generasi Baby Boomer (1946-1964), Generasi X (1965-1980), Generasi Y atau dikenal generasi milenial (19811995), Generasi $Z$ disebut sebagai generasi internet(1995-2010), dan GenerasiAlpha(20112025) (Codringtong et al, 2004). Penelitian ini memiliki fokus penelitian kepada Generasi $\mathrm{Z}$ yang juga dikenal sebagai digital natives, karena mengalami perkembangan bersamaan dengan kemunculan teknologi internet sehingga mampu menggunakan teknologi sama alaminya 
dengan bernapas (Tapscott, 2013).

Karakteristik generasi Z sebagai generasi yang sebenar-benarnya generasi internet. Jika generasi sebelumnya (milenial) berada pada peralihan teknologi dari kondisi sebelum dan sesudah internet, maka Generasi Z sudah tumbuh beriringan dengan keberadaan internet (Sawyer et al., 2018). Kondisi ini menyebabkan Generasi Z memiliki karakter yang akrab dengan teknologi, fleksibel, cerdas, toleran, dan berjejaring di dunia virtual. Berbeda dengan generasi lainnya, Generasi $\mathrm{Z}$ atau Zoomers memiliki pengaruh besar bagi orang-orang di sekitarnya, hal ini dikarenakan kekayaan informasi yang didapat dengan mudah dari terpaan internet.

Zoomers dikenal dengan budayanya dalam berjejaring virtual, jika mengalami sesuatu baik atau buruk maka generasi ini tidak tinggal diam, melainkan berbagi dan mengungkapkan ceritanya di media social (Lawsky, 2008). Generasi Z menggunakan media sosial untuk menjalin hubungan dengan komunitas global dan melakukan eksplorasi kreatif dari hubungan tersebut. Zoomers saling berbagi pesan, foto, dan video untuk saling mengabarkan kondisi yang terjadi di sekitarnya kepada masyarakat dari seluruh penjuru dunia. Pola pikir Generasi Z yang lebih global, tidak menjadikan pengelompokan identitas gender, ras, agama, dan orientasi seksual sebagai indikator. Generasi $\mathrm{Z}$ bahkan menjadikan selebgram atau influencer sebagai panutan dan pembelajaran dalam mendefinisikan dirinya, mereka mengaitkan identitas dengan sesuatu yang dianggap menarik (Tulgan, 2013).

Berdasarkan data United Nations, pada tahun 2020 Generasi Z menduduki jumlah populasi $32 \%$ atau mencapai angka 7,7 miliar jiwa di seluruh dunia, melampaui jumlah generasi milenial. Dengan karakteristik Generasi $\mathrm{Z}$ yang berbeda dengan Generasi Milenial, maka dibutuhkan pendekatan strategi komunikasi pemasaran yang juga berbeda Donovan mengemukakan trend 2020 strategi komunikasi pemasaran influencer marketing bagi Generasi Z (Donovan, 2020). Dengan kemudahan akses informasi dan teknologi, menyebabkan Generasi Z menjadi generasi yang kreatif, rajin, dan open-minded sehingga terdapat beberapa pendekatan yang perlu dilakukan.

Pertama, Generasi Z lebih tertarik dengan platform yang memiliki interkonektifitas yang tinggi, seperti Instagram, YouTube, dan TikTok. Minat ini sejalan dengan karakteristik attention span Generasi Z yang hanya mencapai 8 detik (Fromm \& Read, 2018). Kedua, pengiklan perlu menentukan influencer yang paling sesuai dengan karakteristik Generasi Z potensial. Ketiga, Generasi $\mathrm{Z}$ sangat membutuhkan kejujuran. Generasi Z memiliki kemampuan 
literasi yang baik dengan lebih mengandalkan ulasan atau review yang interaktif, jujur, dan sungguh-sungguh daripada hanya menonjolkan visual foto dengan template caption yang ditentukan oleh pengiklan. Pada akhirnya, Generasi $\mathrm{Z}$ adalah generasi yang paling akrab dengan konsep influencer, bahkan tidak sedikit dari Generasi Z yang ingin menjadi influencer dari diri mereka. Keunikan generasi $\mathrm{Z}$ dibandingkan generasi-generasi sebelumnya ini yang membuat penelitian dengan tujuan mengetahui efektivitas strategi komunikasi pemasaran celebrity endorsement di Instagram terhadap generasi $\mathrm{Z}$ ini perlu dilakukan.

\section{METODE PENELITIAN}

Penelitian ini menggunakan pendekatan mixed method, yang merupakan langkah penelitian dengan menggabungkan dua bentuk pendekatan dalam penelitian, yakni menggabungkan pendekatan kuantitatif dengan kualitatif dalam satu serangkaian penelitian (Creswell, 2010). Penelitian ini menggunakan desain riset mixed method explanatory. Desain explanatory digunakan untuk tujuan penelitian yang dilakukan untuk menguraikan, mengelaborasi, atau menjelaskan temuan kuantitatif (Neuman, 2014).

Tipe strategi eksplanatori yang digunakan adalah tipe eksplanatoris sekuansial (sequential explanatory strategy). Metode ini dilakukan dengan mengolah data yang diperoleh dari metode kuantitatif survei dengan menggunakan instrumen yang berupa kuisioner online dengan 13 pertanyaan yang disebarkan kepada populasi yang sesuai dengan tujuan kriteria responden. Selanjutnya, peneliti mengumpulkan data kualitatif dari responden dengan memberikan lima pertanyaan deskriptif berdasarkan variabel efektivitas celebrity endorsement sebagai dimensi pada pertanyaan kualitatif.

Objek penelitian ini adalah kontenkonten celebrity endorsement yang dipilih dari beberapa influencer dengan jumlah pengikut melebihi 20.000 pengguna. Sedangkan subjek penelitian ini merupakan sampel yang dipilih dengan menggunakan teknik purposive random sampling dengan kriteria responden yang merupakan Mahasiswa Fakultas Ilmu Komunikasi Universitas Padjadjaran yang lahir di antara tahun 2000-2002 atau merupakan mahasiswa angkatan 2018-2020 serta aktif dalam menggunakan Instagram. Pemilihan populasi tersebut didasari oleh asumsi bahwa Mahasiswa Fakultas Ilmu Komunikasi Universitas Padjadjaran memahami bentukbentuk pesan komunikasi sehingga dapat membedakan dan mengklasifikasi konten endorsement dengan yang bukan merupakan konten endorsement pada unggahan influencer.

Pemilihan jumlah sampel menggunakan Rumus Slovin dengan jumlah populasi 1500 
orang dengan alpha 10\% sehingga didapat jumlah responden minimal sebesar 93,75 atau dibulatkan menjadi 94 responden. Dari sebaran kuesioner yang dilakukan secara online, peneliti berhasil mengumpulkan 100 jawaban responden yang terbagi ke dalam dua tipologi metode penilaian, pertama adalah 13 item pernyataan di mana responden memberikan skor sejauh mana persetujuan terhadap item pernyataan tersebut. Skor diberikan dalam bentuk skala Likert dari 1-5 dengan nilai skor 1 merupakan sangat tidak setuju dan skor 5 yang berarti sangat setuju. Bagian kedua berupa pertanyaan terbuka yang memberi ruang bagi responden untuk menuliskan jawabannya dalam bentuk deskriptif. Langkah ini sebagai bentuk penjelasan dari apa yang sebenarnya diinginkan dan diharapkan oleh responden.

Uji validitas menunjukkan seberapa sesuai instrumen operasionalisasi peneliti dengan pengukuran yang dibutuhkan untuk menggambarkan keadaan sesungguhnya (Neuman, 2003). Pengukuran ini dilakukan dengan melakukan penilaian terhadap setiap item pertanyaan pada kuesioner pre-test sejumlah 30 responden dengan menghitung nilai r menggunakan SPSS 26 yang kemudian dibandingkan dengan $\mathrm{r}$ tabel dari rumus $\mathrm{df}=\mathrm{N}$ - 2 dengan derajat signifikansi 5\% atau alpha 0,05 sehingga didapat besaran $r$ tabel adalah sebesar 0,3061. Dari 12 item pertanyaan, ditemukan bahwa seluruh hasil $\mathrm{r}$ hitung dari item pertanyaan lebih besar dari nilai $r$ tabel yakni sebesar 0,3061. Dengan ini disimpulkan bahwa item pertanyaan yang digunakan dalam kuesioner valid dan dapat digunakan.

Selanjutnya, kuesioner akan dilakukan uji reliabilitas untuk mengetahui apakah kuesioner penelitian dapat menyebabkan jawaban responden $\mathrm{t}$ mencapai nilai konsisten atau stabil dari waktu ke waktu. Uji reliabilitas diukur dengan menggunakan rumus Cronbach's Alpha. Pengujian dilakukan pada item pertanyaan dari operasionalisasi variabel celebrity endorsement pada 30 responden dan dapat bernilai reliabel apabila memiliki nilai akhir Cronbach's Alpha > dari 0,600 (Maholtra, 2010). Dari data responden yang diujikan hasil alpha hitung adalah sebesar 0,862 sehingga bernilai lebih besar dari alpha standar 0,600. Dengan demikian item-item dari variabel yang digunakan pada kuesioner sudah dinyatakan reliabel karena konsisten memberikan jawaban yang stabil sehingga dapat dapat dipercaya untuk digunakan berulang kali.

\section{HASIL PENELITIAN}

Secara demografis, dari seratus responden diketahui sebanyak 74\% responden berjenis kelamin perempuan dan $26 \%$ responden berjenis kelamin laki-laki, dengan ini hasil penelitian tidak dapat mewakili Generasi Z berdasarkan gender. Selanjutnya adalah karakteristik 
berdasarkan tahun kelahiran, dengan persentase terbanyak adalah 56\% yang lahir di tahun 2001, diikuti 25\% responden lahir di tahun 2002, dan 19\% responden lahir di tahun 2000. Dengan ini, total keseluruhan responden termasuk ke dalam katagori generasi Z. Karakteristik demografi selanjutnya berdasarkan domisili, sebanyak $46 \%$ responden berdomisili di Jawa Barat, 44\% responden dari Jabodetabek, 2\% responden dari Sumatera Barat, dan masing-masing 1\% responden dari Banten, Jawa Timur, Sulawesi Selatan, Papua, Pekanbaru, Batam, Sumatera Selatan, dan Jambi.

Identifikasi responden selanjutnya dilihat berdasarkan durasi lama waktu tiap responden dalam membuka Instagram, hasil menunjukkan sebanyak 58\% responden membuka Instagram dengan durasi 2-6 jam dalam sehari, 29\% membuka Instagram kurang dari 2 jam dalam sehari, dan sebanyak $13 \%$ responden membuka Instagram lebih dari 6 jam dalam sehari.

Peneliti juga menanyakan jumlah celebrity endorser yang diketahui oleh responden, hasil menunjukkan sebanyak 75\% responden mengetahui lebih dari 10 celebrity endorser, diikuti 20\% mengetahui 5-10 jumlah celebrity endorser, dan sebanyak 5\% responden mengetahui kurang dari 5 celebrity endorser. Dengan kata lain sebagian besar responden sudah mengetahui konten-konten endorsement yang dilakukan oleh celebrity endorser.
Penilaian pada efektivitas strategi komunikasi pemasaran celebrity endorsement terhadap Generasi Z menggunakan pengolahan data melalui instrumen statistik. Langkah pengujian statistik dilanjutkan dengan pengolahan data yang diperoleh dari kuesioner yang dihitung untuk mendapatkan frekuensinya. Setiap jawaban telah diganti dengan skor menggunakan skala Likert (Malhotra, 2010) dengan nilai 1 untuk menggambarkan sangat tidak setuju dan 5 untuk menggambarkan sangat setuju. Sebagai pedoman dalam menentukan tingkat efektivitas variabel celebrity endorsement, maka dipergunakan skala penilaian dan katagori pengukuran dengan membuat tabel rentang skala dalam melihat tiap item pertanyaan dengan rumus panjang interval (nilai tertinggi dikurang nilai terendah dibagi jumlah kelas) (Simamora, 2005). Sehingga didapatkan hasil panjang interval sebesar 0,8 . Selanjutnya rentang ini akan digunakan untuk menganalisis penilaian efektivitas dari setiap item pernyataan kuantitatif yang diajukan dalam kuesioner. Adapun hasil pengkatagorian nilai kelas rata-rata dapat dilihat pada tabel 1 .

Tabel 1 Rentang Kelas Penilaian Item

\begin{tabular}{cc}
\hline Nilai Mean & Kategori \\
\hline $1<$ mean $\leq 1,8$ & Sangat Rendah \\
$1,8<$ mean $\leq 2,6$ & Rendah \\
$2,6<$ mean $\leq 3,4$ & Ragu-ragu \\
$3,4<$ mean $\leq 4,2$ & Tinggi \\
$4,2<$ mean $\leq 5$ & Sangat Tinggi \\
\hline
\end{tabular}

Sumber: Olahan Peneliti, 2020 
Dalam implementasi strategi pemasaran, celebrity endorsement dapat meningkatkan efektivitas iklan jika terdapat kesesuaian antara karakter celebrity dengan nilai-nilai dari brand yang diiklankan (Belch \& Belch, 2017). Pengiklan perlu mempertimbangkan indikator-indikator yang dapat memberikan dampak positif bagi pelaksanaan iklan dalam merancang implementasi strategi pemasaran celebrity endorsement yang dilakukan. Adapun Ohanian (1990), McCracken (1989), Kamins, (1990) menyebutkan enam dimensi yang dapat digunakan dalam menilai variabel celebrity endorsement, yaitu dimensi familiarity, likeability, match up, dan familiarity yang dapat digunakan untuk memberikan penilaian terhadap strategi komunikasi pemasaran celebrity endorsement terhadap persepsi Generasi Z.

Berikut adalah analisis peneliti dari tiap dimensi pengukuran variabel celebrity endorsement berdasarkan hasil penilaian kuantitatif dan jawaban kualitatif deskriptif dari Generasi Z:

Dimensi familiarity. Dalam menilai efektivitas strategi pemasaran celebrity endorsement, pertama perlu ditinjau sejauh mana dari daya tarik (attractiveness) konten celebrity endorsement diakui oleh responden. Daya tarik (attractiveness) yang merepresentasikan atribut yang menarik dari celebrity endorser yang dapat diukur dari familiarity yang dilihat dari sejauh mana khalayak mengenal celebrity endorser yang kerap digunakan oleh brand sebagai medium bantu promosi produknya. Peneliti membagi dimensi familiarity menjadi dua pernyataan yang merepresentasikan indikator dari familiarity, yaitu frekuensi dan keakraban responden dalam melihat konten iklan endorsement.

Hasil menunjukkan bahwa rerata penilaian Generasi Z terhadap frekuensi banyaknya bentuk iklan endorsement yang ditemukan adalah sebesar 4,55 sehingga masuk pada kategori sangat tinggi. Hasil ini menunjukkan bahwa Generasi Z mengetahui dan sering terpapar konten pemasaran dalam bentuk celebrity endorsement. Indikator pernyataan kedua adalah mengenai familiaritas responden terhadap konten celebrity endorsement. Peneliti memberikan pernyataan bahwa celebrity endorsement yang sering terlihat adalah sosok yang akrab dengan responden. Hasil menunjukkan bahwa rerata skor berada pada posisi 3,09 atau termasuk ke dalam katagori ragu-ragu. Hal ini merepresentasikan asumsi bahwa responden tidak sepenuhnya merasa akrab dengan celebrity endorser yang kerap digunakan oleh pengiklan. Dengan ini, untuk efektivitas celebrity endorsement dari indikator dimensi familiarity mendapat skor 3,82 atau masuk katagori tinggi sehingga Generasi Z 
setuju bahwa konten celebrity endorsement familiar dengan responden.

Dimensi Likeability. Dimensi ini menilai daya tarik dari konten celebrity endorsement adalah likeability (McCracken, 1989). Dimensi ini dinilai berdasarkan faktor yang menimbulkan ketertarikan, pengaruh, atensi, dan dampak positif terhadap pesan berdasarkan atribut fisik celebrity endorser. Likeability merepresentasikan faktor-faktor atribut dan visual dari konten celebrity endorsement yang akan disukai oleh Generasi Z. Peneliti menilai dimensi likeability dengan membagi ke dalam dua indikator pertanyaan.

Pertama, adalah menilai sejauh mana Generasi Z menyukai bentuk iklan dengan strategi promosi endorsement. Indikator ini mendapat skor rerata sebesar 2,38 atau termasuk katagori rendah. Skor ini membuktikan bahwa Generasi Z kurang menyukai strategi promosi endorsement yang ada pada praktik periklanan endorsement saat ini. Berdasarkan ulasan deskriptif dari jawaban responden, peneliti menarik beberapa alasan yang paling banyak muncul dari jawaban responden terkait hal yang kurang disukai dari praktik pemasaran endorsement yang saat ini dilakukan. Adapun akumulasi alasan dari responden tersebut adalah dikarenakan tampilan pesan strategi endorsement yang tidak menarik, bisa dari konsep yang tidak jelas, foto yang asal-asalan, dan menggunakan template dari pengiklan. Seperti yang dikatakan informan sebagai berikut:

"Sesuai dengan konsep dan barang yang diiklankan. Selain itu, aku lebih suka ngeliat iklan yang difoto secara proper jd secara gak langsung aku tau kalo influecer/brand tsb gak setengah-setengah dalam membuat dan mempromosikan barangnya." (Wawancara tertulis dengan Rasya Fajri Shabyra pada 30 Mei 2020).

Kedua, adalah indikator pernyataan bahwa penempatan iklan endorsement dirasa sudah sesuai dengan ketertarikan generasi $\mathrm{Z}$ terhadap latar belakang kehidupan celebrity endorser. Hasil menunjukkan rerata senilai 1,61 atau termasuk ke dalam katagori sangat rendah. Skor ini merepresentasikan Generasi $\mathrm{Z}$ yang tidak merasa bahwa celebrity endorser yang dipilih merupakan sosok yang sebelumnya disukai karena karya-karyanya. Hal ini ditunjukkan dari jawaban deskriptif responden yang mengatakan bahwa pengiklan tidak mempertimbangkan penggunaan celebrity endorsement yang sesuai dengan target khalayaknya, sehingga salah sasaran. Sehingga celebrity endorsement yang saat ini digunakan bukanlah representasi sosok yang disukai oleh responden.

Dalam menilai tingkat ketertarikan Generasi Z terhadap atribut yang berkaitan dengan konten endorsement, dimensi selanjutnya adalah familiarity (McCracken, 1989). Dimensi ini digunakan untuk menilai efektivitas penyampaian pesan berdasarkan 
faktor kesamaan Generasi Z dengan celebrity endorser. Peneliti menilai dimensi familiarity dengan membagi alat ukur dalam dua indikator, pertama adalah kesamaan Generasi Z dengan style/taste dari celebrity endorser dan yang kedua adalah kemiripan konten endorsement dengan konten lainnya yang sebelumnya sudah disukai oleh Generasi Z.

Hasil menunjukkan bahwa pada item indikator pertama mendapat rerata sebesar 2,4 yang masuk dalam kategori rendah. Hal ini menunjukkan bahwa Generasi Z kurang setuju bahwa pemilihan celebrity endorser sudah sesuai dengan selera/gaya hidup Generasi Z. Jawaban ini terefleksi dari jawaban deskriptif dari kuisioner yang mengatakan bahwa celebrity endorsement banyak yang tidak sesuai dengan Generasi Z sebagai target pasar, Generasi Z berpendapat bahwa banyak endorser yang berlebihan sehingga tidak sesuai dengan selera dan gaya yang disukai oleh responden (style berupa pilihan gaya atau dapat berupa atribut tampilan endorser). Adapun alasan salah satu informan adalah sebagai berikut:

"Instagram memiliki algoritma yang bisa dibilang sangat canggih. Hanya dengan menyukai beberapa post atau mengikuti public figure dengan job tertentu, maka konten yang ditampilkan kepada kita akan sangat berbasis pada hal tersebut. Saya akan sangat senang apabila para brand yang mengedepankan celebrity endorsement ini lebih memfilter lagi siapa yang akan mereka jadikan "face of the brand"-nya agar tepat sasaran." (Wawancara tertulis dengan Denisse Rachel pada 31 Mei 2020)
Indikator kedua mendapat skor rerata sebesar 2,38 atau katagori rendah. Hasil ini menunjukkan bahwa Generasi Z kurang setuju bahwa pesan endorsement sudah sesuai dengan konten keseharian yang disukai oleh Generasi Z. Mayoritas jawaban deskriptif dari responden mengatakan bahwa konten endorsement bukanlah konten yang natural atau asli dibuat oleh celebrity endorser. Jawaban mayoritas selanjutnya adalah pesan dinilai terlalu dipaksakan dengan format yang berasal dari pengiklan, padahal Generasi Z menyukai pesan yang inspiratif dan tulus dari sosok selebgram yang diikutinya.

Ohanian mendefinisikan kredibilitas celebrity endorser sebagai sejauh mana celebrity endorser dilihat mempunyai keahlian sesuai pada pokok bahasan di iklan dan memiliki rasa yang bisa dipercaya sehingga membagikan saran yang objektif tentang subjek (Ohanian, 1990). Sementara itu, Goldsmith mengemukakan kredibilitas endorser sebagai seberapa besar konsumen percaya terhadap endorser untuk menyampaikan informasi kepada konsumen (Goldsmith et al., 2000). Indikator lainnya dari kredibilitas adalah keahlian (expertise). Keahlian sebagai faktor penting yang dapat menangkap atensi khalayak karena keahlian dianggap realita yang menunjukkan kehidupan sebenarnya. Keahlian dapat mengundang khalayak untuk 
turut dmembentuk keterampilan, memberikan kesesuaian wawasan serta pengalaman yang dimiliki celebrity endorser untuk dihubungkan dengan pesan (value) dari konsep produk yang diiklankan.

Peneliti membagi ke dalam dua indikator pernyataan, pertama adalah kesesuaian pesan yang disampaikan dengan latar belakang keahlian dari celebrity endorser, hasil menunjukkan besaran rerata 2,43 atau termasuk katagori rendah. Mayoritas dari responden yang merasa bahwa banyak celebrity yang melakukan review atau ulasan pada brand yang tidak sesuai dengan kesehariannya, atau dengan kata lain tidak ada hubungannya dengan latar belakang keterampilan/kegiatan/ keahlian dari celebrity endorser. Ketidaksesuaian ini menurunkan kepercayaan dan kredibilitas pesan pada strategi pemasaran celebrity endorsement. Seperti yang diharapkan oleh informan sebagai berikut:

"Kejujuran \& non-script, kalau memang bagus ya bilang bagus kalau memang kurang, menjelaskan secara baik-baik tapi tetep menunjukan keunggulan barang serta memberi masukan." (Wawancara tertulis dengan Rasya Fajri Shabyra pada 30 Mei 2020).

Indikator pernyataan kedua mengenai kejujuran pesan yang disampaikan pada konten endorsement. Hasil menunjukkan besaran rerata skor sebesar 1,76 atau masuk kategori sangat rendah. Dengan demikian, Generasi Z merasa bahwa praktik celebrity endorsement tidak memberikan informasi atau ulasan yang jujur dan apa adanya. Mayoritas responden merasa bahwa celebrity endorser melakukan praktik endorsement hanya karena faktor perjanjian karena dibayar semata atau karena uang. Review bukan berasal dari hasil penggunaan sebenarnya. Dengan karakteristik Generasi $\mathrm{Z}$ yang sangat dekat dengan akses informasi, ulasan yang tidak jujur menjadi poin yang tidak disukai oleh Generasi Z.

Indikator selanjutnya dikemukakan oleh Kamins (1990) disebut dengan istilah match-up di mana penyampaian pesan iklan yang efektif dapat diperoleh dari asosiasi yang sesuai antara celebrity endorser dengan fitur produk atau brand yang diiklankan sehingga dapat saling memberikan komplemen. Dengan kata lain, jika celebrity endorser dengan pesan iklan dapat dihubungkan dengan sukses maka citra brand dapat mendapat dampak yang positif sehingga penerapan iklan dapat berjalan dengan efektif (Bertrand, 1992).

Hasil menunjukkan bahwa untuk indikator kesesuaian value/prinsip hidup celebrity endorser mendapat nilai rerata 2,22 atau rendah. Hal ini membuktikan bahwa Generasi Z kurang merasa bahwa praktik pesan endorsement sudah sesuai dengan latar belakang celebrity endorser yang digunakan. Mayoritas responden menjawab bahwa bentuk promosi celebrity endorsement yang ditemukan sering tidak 
berhubungan dengan value hidup celebrity endorser yang ditunjukkan pada kesehariannya sehingga terkesan hanya memenuhi kebutuhan perjanjian endorse semata. Seperti yang disampaikan informan sebagai berikut:

"Sometimes it feels like they're just being paid to promote those stuffs (they are tho), it doesnt feel sincere at all or it's hard to tell if they're really use and love the products or they're just pretending to" (Wawancara tertulis dengan Nabila Raihan Kandi pada 1 Juni 2020).

Sementara indikator pesan iklan endorsement relate dengan kehidupan celebrity endorser mendapat nilai rerata 3,12 atau netral. DenganinimenunjukkanbahwaGenerasiZraguragu terhadap efektivitas pesan endorsement jika dilihat dari asosiasi endorser dengan brand. Endorser belum mampu memberikan nilai positif yang terasosiasi dengan brand yang ia promosikan. Mayoritas Generasi Z merasa brand belum terasosiasi dengan endorser jika dilihat dari praktik endorsement yang terjadi saat ini. Padahal, jika melihat karakteristik Generasi Z, mereka merupakan generasi yang memiliki tingkat literasi yang lebih tinggi dari generasi sebelumnya (Fromm dan Read, 2018) sehingga konten perlu disesuaikan dengan karakteristik mereka agar dapat diperhatikan.

Indikator terakhir disampaikan oleh (McCracken, 1989) adalah tentang familiarity, di mana iklan yang efektif harus dapat menyampaikan konteks pesan sebagai konten yang berkualitas sehingga dapat memberikan makna pada pesan yang disampaikan dan dapat diterima oleh khalayak. Dimensi ini dilakukan pengukuran berdasarkan dua indikator pernyataan, pertama adalah efektivitas penggunaan atribut pesan endorsement yang dapat dilihat dari penggunaan properti, caption foto, sudut pengambilan gambar, tema foto, dan gaya foto. Selanjutnya indikator yang kedua adalah pengaruh celebrity endorsement terhadap nilai brand di mata responden.

Hasil dari pengukuran indikator pertama adalah mendapat rata-rata penilaian sebesar 2,42 atau masuk dalam katagori rendah. Dengan ini generasi $\mathrm{Z}$ belum merasa bahwa atribut yang digunakan oleh celebrity endorser sudah membantu penyampaian pesan endorsement dengan optimal. Mayoritas menjawab bahwa praktik endorsement yang ditemukan banyak yang tidak kreatif dan tidak sesuai dengan pesan yang disampaikan. Generasi Z lebih menginginkan pesan iklan yang kreatif dengan tampilan foto/video yang menarik. Kreativitas dapat berupa pemilihan konsep properti, caption foto, sudut pengambilan gambar, dan tema besar foto. Generasi Z tidak menyukai tampilan iklan yang asal-asalan. Salah satu contoh yang direkomendasikan oleh informan adalah dengan bentuk kreatif seperti yang dilakukan olehselebgram@joviadhiguna pada gambar 4. 


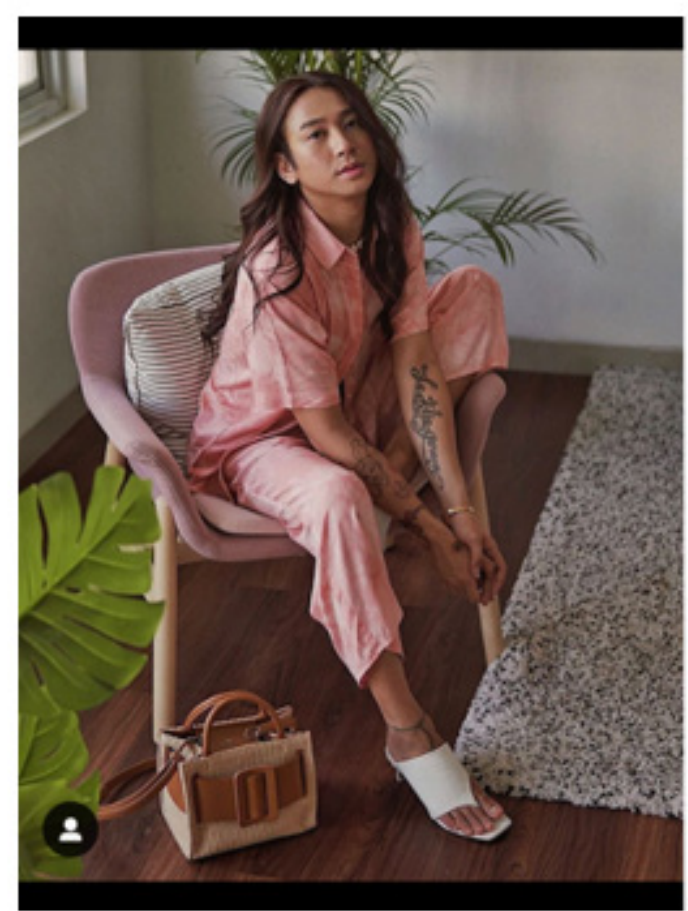

Sumber: Akun Instagram @joviadhiguna

\section{Gambar 4 Foto Unggahan Jovi Adhiguna}

Indikator selanjutnya mendapat nilai rerata sebesar 2,36 yang juga masuk ke dalam katagori rendah. Hal ini menunjukkan bahwa Generasi Z belum merasa pengaruh yang besar dari penggunaan celebrity endorsement dalam promosi iklan. Mayoritas responden menyebut bahwa alasan dari rendahnya efektivitas ini karena banyak praktik periklanan endorsement yang menyelewengkan kualitas dan konsep yang benar dalam produksi iklan tersebut. Seperti yang dikatakan informan berikut ini:

"Saya tidak suka konten endorsement selebgram yang terlalu bertele-tele dan juga konten yang hanya mengcopas caption yang diberikan oleh online shopnya, bukan review jujur terhadap produk yang dipromosikan. saya juga tidak suka konten endorsement yang hanya sekedar promosi dengan menggunakan kata kata yang terkesan "tidak niat" yang menyebabkan barang yang dipromosikan menjadi tidak joviadhiguna $\odot$. Follow

joviadhiguna $\odot$ HAHAHAHAHA TAS AMBOKSING TADI UDAH KUPAKE DULUAN BEBERAPA HARI LALU PAS MEETING DI KANTOR! GAK SABARAN!! DASAR AKU.... ANYWAAAAY THANK YOU @fellice.authentic FOR THE @boyyboutique BAGGGGG!! I LOVE IT SOO MUCH I CUD DIEEEEEEE Kalo kalian nyari designer goods, make sure you guys check em out! Nyari barana va rare dan aak ada di indo iuaa

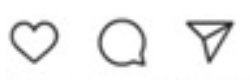

Liked by gabriellaolivia and others

1 DAY AGO

Add a comment...

menarik" (Wawancara tertulis dengan Zahrah Nur Aulia Dewi, 1 Juni 2020)

\section{SIMPULAN}

Berdasarkan hasil penelitian yang telah dilakukan, dapat disimpulkan bahwa penilaian Generasi $\mathrm{Z}$ terhadap efektivitas penggunaan bentuk strategi komunikasi pemasaran celebrity endorsement di Instagram relatif rendah. Skor penilaian tertinggi diperoleh oleh dimensi familiarity. Hal ini menunjukkan bahwa Generasi Z familiar dengan bentuk iklan endorsement dan praktik penerapannya di Instagram saat ini. Skor terendah diperoleh oleh dimensi likeability. Hal ini membuktikan bahwa Generasi Z kurang menyukai bentuk strategi pemasaran celebrity endorsement seperti yang 
dilakukan saat ini.

Dengan ini terbukti bahwa Generasi Z kurang setuju bahwa celebrity endorsement di Instagram merupakan bentuk strategi komunikasi pemasaran yang efektif. Hal ini dikarenakan beberapa faktor, di antaranya ketidakjujuran ulasan yang diberikan oleh celebrity endorser karena terkesan dibuatbuat atau sekedar memenuhi kontrak dengan pengiklan, konten yang tidak kreatif karena menggunakan format dan diarahkan oleh pengiklan, dimensi visual foto atau video yang tidak menarik, bentuk pesan yang tidak sesuai dengan gaya konten celebrity endorser yang lainnya, pesan endorsement yang tidak sesuai dengan latar belakang celebrity endorsement, penjelasan produk/brand yang dangkal, serta pesan iklan yang terlalu banyak dan mengalahkan konten pribadi sehingga cenderung spamming.

Dari hasil penelitian dan wawancara terdapat beberapa saran dari generasi $\mathrm{Z}$ yang dapat diimplementasikan oleh pengiklan dalam melaksanakan praktik strategi komunikasi pemasaran celebrity endorsement di Instagram ada beberapa saran agar pesan dapat lebih menarik dan diterima. Dengan demikian iklan dapat tepat sasaran dan memberikan dampak yang positif bagi citra promosi brand terhadap Generasi Z. Saran tersebut adalah, Pertama, pengiklan harus menentukan konsep yang tepat dalam menyusun nilai (value) yang ingin disampaikan melalui pesan endorsement. Kedua, konsep harus disesuaikan dengan celebrity endorser yang akan dipilih, pengiklan harus melihat latar belakang keahlian atau keseharian celebrity endorser apakah sesuai dengan value brand atau tidak. Ketiga adalah proses pengolahan ide dan konsep pesan menjadi unggahan di media social. Dalam proses ini Generasi Z menyarankan bahwa pesan harus memuat cerita yang kreatif, inspiratif, dan interaktif berdasarkan latar belakang kehidupan celebrity endorser, pesan juga harus menonjolkan kesesuaian gaya bahasa, serta gaya visual yang sejalan dengan konten sehari-hari. Ketiga, jika sudah dirumuskan dengan benar maka masuk ke tahap publikasi, publikasi iklan tidak boleh mengalahkan frekuensi publikasi pribadi. Endorser perlu menunjukkan bahwa produk/brand benar-benar sudah dicoba atau digunakan sehingga dapat meningkatkan kredibilitas dari pesan iklan endorsement tersebut. Informan memberikan beberapa referensi celebrity endorser yang sudah melakukan praktik celebrity endorsement di Instagram yang sesuai dengan preferensi Generasi Z. Beberapa diantaranya adalah @joviadhiguna,@ojmo, @amrazing,@ rezachandika,@aulion, @agunghapsah,@ yogaarizona,@rachelvennya,dan lain-lain. 


\section{DAFTAR PUSTAKA}

Adrianson, L., \& Hjelmquist, E. (1991). Group processes in face-to-face and computer-mediated communication. Behaviour and Information Technology, 10(4), 281-296. https://doi. org/10.1080/01449299108924290

Belch, G., \& Belch, M. (2017). Advertising and Promotion: An IMC Perspective. In Advertising and promotion : an integrated marketing communications perspective.

Budiman, R., \& Erdiansyah, R. (2021). Pengaruh Celebrity Endorser, Kualitas Pesan Iklan, Kreativitas Iklan terhadap Efektivitas Iklan Gojek Cerdikiawan. Prologia, 5(1), 88. https://doi.org/10.24912/pr.v5i1.8140

Childers, C. C., Lemon, L. L., \& Hoy, M. G. (2019). \#Sponsored \#Ad: Agency Perspective on Influencer Marketing Campaigns. Journal of Current Issues and Research in Advertising, 40(3), 258-274. https://doi.org/10.1080/10641734.2018.15 21113

Donovan, S. (n.d.). Changing the Game: Influencer Marketing for Generation Z.

Drago, E. (2015). The effect of technology on face-to-face communication. The Elon Journal of Undergraduate Research in Communications.

Friedman, H. H., \& Friedman, L. (1979). Endorser effectiveness by product type. Journal of Advertising Research.

Fromm, J., \& Read, A. (2018). Marketing to Gen Z: The Rules for Reaching This Vast and Very Different Generation of Influencers. AMACOM.

Gilly, M. C., Graham, J. L., Wolfinbarger, M. F., \& Yale, L. J. (1998). A dyadic study of interpersonal information search. Journal of the Academy of Marketing Science. https:// doi.org/10.1177/0092070398262001

Glueck, W. F., \& Jauch, L. R. (1989). Strategic Management and Business Policy. McGraw-Hill Education.

Goldsmith, R. E., Lafferty, B. A., \& Newell, S. J. (2000). The impact of corporate credibility and celebrity credibility on consumer reaction to advertisements and brands. Journal of Advertising, 29(3), 4354. https://doi.org/10.1080/00913367.2000 .10673616

Greenwood, P. (2019, May). Why influencers are losing their influence - We Are Social.

Hennig-Thurau, T., Gwinner, K. P., Walsh, G., \& Gremler, D. D. (2004). Electronic word-of-mouth via consumer-opinion platforms: What motivates consumers to articulate themselves on the Internet? Journal of Interactive Marketing. https:// doi.org/10.1002/dir.10073

Kamins, M. A. (1990). An investigation into the "match-up" hypothesis in celebrity advertising: When beauty may be only skin deep. Journal of Advertising. https://doi.or g/10.1080/00913367.1990.10673175

Kaplan, A. M., \& Haenlein, M. (2010). Users of the world, unite! The challenges and opportunities of Social Media. Business Horizons, 53(1), 59-68. https://doi. org/10.1016/j.bushor.2009.09.003

Lawsky, D. (2008). American Youth Trail in Internet Use: survey. Reuters.

López, M., \& Sicilia, M. (2014a). Determinants of E-WOM influence: The role of consumers' internet experience. Journal of Theoretical and Applied Electronic Commerce Research. https://doi. org/10.4067/S0718-18762014000100004

López, M., \& Sicilia, M. (2014b). Determinants of E-WOM influence: The role of consumers' internet experience. 
Journal of Theoretical and Applied Electronic Commerce Research, 9(1), 28-43. https://doi.org/10.4067/S071818762014000100004

McCracken, G. (1989). Who is the Celebrity Endorser? Cultural Foundations of the Endorsement Process. Journal of Consumer Research. https://doi.org/10.1086/209217

McMillan, S. J., \& Childers, C. C. (2017). A Decade of Change and the Emergence of Digital Media: Analysis of Trade Press Coverage of the Advertising Industry, 2005-2014. Journal of Interactive Advertising. https://doi.org/10.1080/15252 019.2017.1315320

Mulyo, P. D. (2016). Endorser Sebagai Affirmative Action Dalam Komunikasi Bisnis. Jurnal Nomosleca, 2(2), 68-70.

Neuman, W. (2014). Social Research Methods: Qualitative and Quantitative Approaches. In Teaching Sociology (Vol. 30). https:// doi.org/10.2307/3211488

Ohanian, R. (1990). Construction and validation of a scale to measure celebrity endorsers' perceived expertise, trustworthiness, and attractiveness. Journal of Advertising. https://doi.org/10.1080/00913367.1990.10 673191

Pawar, A. (2014, March). Lecture 1 marketing communications theory.

Rahmawati, M., \& Lestari, S. P. (2021). Pengaruh penggunaan selebgram terhadap minat beli konsumen. Jurnal Ekonomi Perjuangan, 2(2), 138-153.

Ramadhan, A., Naswandi, C. N., \& Herman, C. M. (2020). Fenomena endorsement di instagram story pada kalangan selebgram. Jurnal Kareba, 9(2).

Ridha, A., Perdana, A. H., \& As'ad, A. (2018). Celebrity Endorser Pada Jejaring
Sosialinstagram Untuk Menarik Minat Pembelian Calon Konsumen. Jurnal Economic Resource, 1(1), 86-96. https:// doi.org/10.33096/jer.v1i1.61

Sammis, K., Lincoln, C., \& Pomponi, S. (2015). Influencer Marketing for Dummies. In John Wiley \& Sons.

Santoso, R. (2020). Review of Digital Marketing \& Business Sustainability of E-Commerce During Pandemic Covid19 In Indonesia. Jurnal Ilmu Ekonomi Terapan, 5(2), 36-48. Sawyer, S.M.,Azzopardi,P. S., Wickremarathne, D., \& Patton, G. C. (2018). The age of adolescence. The Lancet Child and Adolescent Health, 2(3), 223-228. https:// doi.org/10.1016/S2352-4642(18)30022-1

Sen, S., \& Lerman, D. (2007). Why are you telling me this? An examination into negative consumer reviews on the web. Journal of Interactive Marketing. https:// doi.org/10.1002/dir.20090

Shimp, T. A., Wood, S. L., \& Smarandescu, L. (2007). Self-generated advertisements: Testimonials and the perils of consumer exaggeration. Journal of Advertising Research, 47(4), 453-461. https://doi. org/10.2501/S002184990707047X

Sofwan, I. (2013). Kesehatan Jiwa Remaja. Kemas, 5(1), 49-57. http://journal.unnes. ac.id/index.php/kemas\%0AKESEHATAN

Tapscott, D. (2013). Grown Up Digital: Yang Muda Yang Mengubah Dunia. PT Gramedia Pustaka Utama.

Tulgan, B. (2013). Meet Generation Z: The second generation within the giant " Millennial " cohort. RainmakerThinking, Inc.

Vanderstoep, Scott W;Jhonston, D. D. (2009). Research Method for Everyday Life. Jossey Bass. 